Braz J Med Biol Res, April 2012, Volume 45(4) 366-375

doi: $10.1590 / \mathrm{S} 0100-879 \mathrm{X} 2012007500036$

New perspective on the pathophysiology of panic:

merging serotonin and opioids in the periaqueductal gray

F.G. Graeff

The Brazilian Journal of Medical and Biological Research is partially financed by

\section{贵CNPq}

da Ciência e Tecnologia

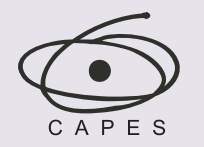

Ministério da Educação
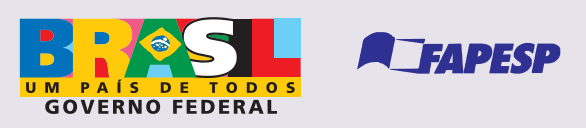

Institutional Sponsors

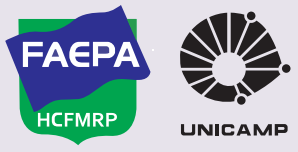

$\oplus$ SHIMADZU
UNICAMP
DFAPESP

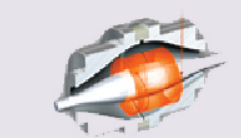

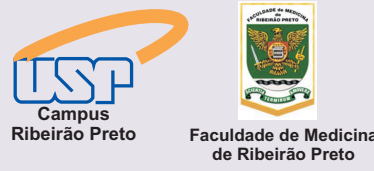

Scielo

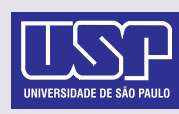

Ribeirão Preto 


\title{
New perspective on the pathophysiology of panic: merging serotonin and opioids in the periaqueductal gray
}

\author{
F.G. Graeff ${ }^{1,2}$ \\ ${ }^{1}$ Faculdade de Medicina de Ribeirão Preto, Universidade de São Paulo, Ribeirão Preto, SP, Brasil \\ ${ }^{2}$ Instituto de Neurociências e Comportamento, Universidade de São Paulo, Ribeirão Preto, SP, Brasil
}

\begin{abstract}
Panic disorder patients are vulnerable to recurrent panic attacks. Two neurochemical hypotheses have been proposed to explain this susceptibility. The first assumes that panic patients have deficient serotonergic inhibition of neurons localized in the dorsal periaqueductal gray matter of the midbrain that organize defensive reactions to cope with proximal threats and of sympathomotor control areas of the rostral ventrolateral medulla that generate most of the neurovegetative symptoms of the panic attack. The second suggests that endogenous opioids buffer normal subjects from the behavioral and physiological manifestations of the panic attack, and their deficit brings about heightened suffocation sensitivity and separation anxiety in panic patients, making them more vulnerable to panic attacks. Experimental results obtained in rats performing one-way escape in the elevated T-maze, an animal model of panic, indicate that the inhibitory action of serotonin on defense is connected with activation of endogenous opioids in the periaqueductal gray. This allows reconciliation of the serotonergic and opioidergic hypotheses of panic pathophysiology, the periaqueductal gray being the fulcrum of serotonin-opioid interaction.
\end{abstract}

Key words: Panic; Animal model; Periaqueductal gray; Serotonin; Opioids

\section{Introduction}

The current concept of panic disorder (PD) as a distinct diagnostic category is based on the results originally reported by Klein and Fink (1) showing that chronic administration of the antidepressantagent imipramine led to improvement of patients who had recurrent episodes of extreme anxiety, named panic attack (PA). This finding led to the pharmacological distinction between PD and chronic anxiety, which has been adopted by contemporary psychiatric classifications.

Although the PA is the hallmark of PD, its occurrence, alone, does not characterize the condition. The Diagnostic and Statistical Manual of Mental Disorders, 4th edition, Text Revision (DSM-IV-TR) (2) criteria for PD state that PAs must be associated with more than 1 month of subsequent persistent worry (anticipatory anxiety) about having another attack and about the consequences of the attacks, as well as with significant behavioral changes related to the attacks, chiefly avoidance of places or situations where having a PA is embarrassing and escape is difficult. When avoidance is generalized, the condition is called agoraphobia.

The PA is a period of intense fear in which 4 of 13 defined symptoms develop abruptly, peaks in less than 10 min from symptom onset, and usually subsides within 30 min. The DSM-IV-TR (2) lists the following symptoms of a PA: palpitation, sweating, trembling, shortness of breath, choking, chest pain, nausea or abdominal distress, dizziness, derealization or depersonalization, fear of losing control or of going crazy, fear of dying, numbness or tingling sensations, chills or hot flashes. Other symptoms that may occur are: diarrhea, cold hands, headache, insomnia, fatigue, intrusive thoughts, and ruminations. During the attack, patients often have an urge to flee or escape and a sense of impending doom, as though they are dying from suffocation or a heart attack.

The neural basis of anticipatory anxiety and avoidance is not fully understood, but there is sound preclinical and clinical evidence implicating the midbrain periaqueductal gray matter (PAG) in the genesis of PAs. The present review focuses on the modulation of PAs by neurotransmitters that work in the PAG, with emphasis on serotonin (5-HT) and endogenous opioids.

Correspondence: F.G. Graeff, Faculdade de Medicina de Ribeirão Preto, USP, Av. Bandeirantes, 3900, 14049-900 Ribeirão Preto, SP, Brasil. Fax: +55-16-3602-3276. E-mail: hegog@hotmail.com 


\section{PAG and panic}

There is compelling experimental evidence obtained for both laboratory animals and human subjects supporting the participation of the PAG in PAs (3). Electrical or chemical stimulation of the dorsal part of the PAG (dPAG), mainly the dorsolateral column, elicits behavioral changes that are reminiscent of a PA. Also, electrical stimulation of the dPAG in human patients undergoing neurosurgery evokes feelings of dread accompanied by neurovegetative manifestations that overlap the symptoms of a PA (Table 1).

More recently, the participation of the PAG in panic has been investigated using structural and functional neuroimaging. In the structural studies, the soundest evidence comes from results obtained with voxel-based morphometry (VBM). This is an automated method of brain segmentation into gray matter, white matter and cerebrospinal fluid compartments that allows the investigation of differences in regional volumes along the whole brain. Using the VBM technique, Protopopescu et al. (4) have described an increase in gray matter volume of the midbrain and rostral pons, comprising the PAG, in panic patients compared to healthy controls. In a similar study by our research group (5), we have also found a relative increase in gray matter volume of midbrain and pons in panic patients compared to healthy subjects. A further study (6) was able to assess separately the volume of gray matter of the dorsal and of the ventral midbrain. The results obtained showed that the relative volume of the dorsal midbrain was larger in the PD group compared to healthy controls, while the volume of the ventral midbrain was not. A significant positive correlation was found between relative dorsal midbrain volume and severity of PD symptoms, and a significant negative correlation between relative dorsal midbrain volume and quality of life scores in PD patients. These findings clearly implicate the dorsal midbrain, where the dPAG lies, in the pathophysiology of PD.

Regarding functional studies, the detection of metabolic dysfunctions in a small structure like the PAG is hampered by the limitations of current neuroimaging techniques. Despite this shortcoming, some studies have reported abnormalities in the midbrain of panic patients. Using $\mathrm{H}_{2}{ }^{15} \mathrm{O}$ positron emission tomography (PET) on lactate-induced panic attacks (see below), Reiman et al. (7) reported activation of several brain areas that organize defensive behavior including the anterior temporal lobe and an area subjacent to the superior colliculi, probably the PAG. A similar study using cholecystokinin tetrapeptide (CCK-4) administration to induce PAs showed activation of the hypothalamus and the PAG (8).

Another PET study investigated regional glucose utilization in patients with PD before and after cognitive behavior therapy (CBT) (9). In 11 of 12 patients who showed improvement, decreased glucose utilization was detected in the right hippocampus, left anterior cingulate cortex, left cerebellum, and midbrain-pons, whereas increased glucose utilization was seen in the bilateral medial prefrontal cortex (PFC). More relevant to the present discussion is the finding of significant correlations between the percent change of glucose utilization in the left medial PFC and changes of anxiety and of the agoraphobia-related subscale of the Panic Disorder Severity Scale, as well as between the percent change of glucose utilization in the midbrain and the number of PAs during the 4 weeks before each scan.

The last results indicate that anticipatory anxiety correlates with activation of the medial PFC while the PA is associated with PAG activation. This concept is strongly supported by the findings of a paradigmatic experiment with healthy volunteers using functional magnetic resonance imaging (fMRI) (10). In the experimental session, a virtual predator is programmed to chase a virtual prey within the alleys of a labyrinth visualized by the participant on a video screen. By manipulating a keyboard to move a triangle representing the prey, the participant was able to avoid a virtual predator, represented by a red dot, with the ability to chase, capture and inflict pain. There were two levels of threat, consisting of either one or three electric shocks being administered to one finger when the virtual prey was caught. The results obtained showed that brain activity shifted from PFC areas (cingulate and orbitofrontal cortices and anterior ventromedial PFC) to the PAG as the predator grew closer to the prey. When the predator was distant, the PFC and the lateral amygdala were activated, more clearly when the expected threat level was low. When

Table 1. Similarities of the symptoms of a panic attack and the effects of electrical stimulation of the periaqueductal gray matter (PAG) in humans and rats.

\begin{tabular}{lll}
\hline Panic attack symptoms & PAG stimulation in humans & PAG stimulation in rats \\
\hline Extreme fear and distress & Dread, terror & Switches off stimulation \\
Urge to flee & Urge to flee & Flight \\
Palpitation & Tachycardia & Tachycardia \\
Sweating & Sweating & \\
Tremor & Sensation of vibration & Tachypnea \\
Shortness of breath or choking & Hyperventilation & Hyperventilation \\
& Apnea & \\
Chest pain or discomfort & Chest and heart pain & Micturition \\
Nausea or abdominal discomfort & Urge to urinate & Defecation \\
& & \\
Chills or hot flushes & "Burn/cold" sensations & \\
\hline
\end{tabular}

Modified from Del-Ben and Graeff (3). 
the predator was close to the prey, the central amygdala and the PAG were activated. This activation was maximal when the highest level of pain was anticipated. Moreover, the degree of PAG activation was positively correlated with the reported intensity of fear and decreased confidence of escape. A further study (11) used a similar experimental setting to test McNaughton and Corr's two-dimensional theory of fear/anxiety (12). One dimension is defensive distance and the other defensive direction, which distinguishes fear from anxiety. In fear, there is only motivation to escape or to avoid the danger source, whereas in anxiety this motivation is in conflict with an opposite tendency to approach the same source of danger. As a model of fear, the escape task described above was used while anxiety was assessed after the virtual prey had been caught by the predator and the persecution was stopped. In addition to regional activity, the fMRI also explored connectivity among brain structures. The results showed that the anxiety condition activated the medial PFC and actively inhibited PAG activation. In contrast, when the predator was close to the pray the PAG was activated and PFC activation was inhibited. These results support the view that anxiety is mainly integrated in the forebrain, whereas panic is chiefly organized in the midbrain.

\section{5-HT and Panic}

Among several neurotransmitters that operate in the PAG, 5-HT is believed to play a key role in PAs for at least two reasons: 1) a theoretical construct about the role of $5-\mathrm{HT}$ in defense proposes that 5-HT inhibits PAG neural networks that coordinate defense reactions against proximal danger and that these networks are the same that bring about the PA $(13,14)$ and 2$)$ antidepressant drugs that are used to treat PD are likely to act by enhancing the action of $5-\mathrm{HT}$ in the brain (15).

The modulation of defense by $5-\mathrm{HT}$ in the dPAG of the rat has been thoroughly reviewed elsewhere (16-18). The evidence supporting the hypothesis that $5-\mathrm{HT}$ inhibits aversion generated by electrical stimulation of the dPAG may be summarized as follows: 1 ) systemically administered drugs that enhance the central action of 5- $\mathrm{HT}$ impair behavioral responses that either decrease or terminate electrical current applied to the dPAG; 2) injection into the dPAG of 5-HT or drugs that stimulate $5-\mathrm{HT}_{1 \mathrm{~A}}$ and/or $5-\mathrm{HT}_{2 \mathrm{~A}}$ receptors increases the least electrical current intensity that elicits flight with dPAG stimulation (aversive threshold); 3) treatments that release $5-\mathrm{HT}$ into the $\mathrm{dPAG}$ have a similar antiaversive effect; 4) escape from the open arm of the elevated T-maze (ETM, see description in the "5-HT and Opioids section"), a task that activates the dPAG and has been pharmacologically validated as an animal model of panic, is impaired by systemically or intracerebrally administered drugs that enhance the action of 5-HT, including several antidepressants that are used to treat PD; 5) the same escape task is facilitated by either systemic injection of the panicogenic agent CCK-8s or intra-PAG administration of the similar agent CCK- 4 ; 6) the inhibitory effect of antidepressants on ETM escape is antagonized by pretreatment with a selective $5-\mathrm{HT}_{1 \mathrm{~A}}$ receptor blocker injected into the dPAG; 7) the sensitivity of $5-\mathrm{HT}_{1} \mathrm{~A}$ and $5-\mathrm{HT}_{2} \mathrm{~A}$ receptors is heightened following chronic (daily injection for 21 days), but not acute, treatment with antipanic drugs, including antidepressants and the panicolytic benzodiazepine derivative alprazolam, a drug that acts primarily on $\mathrm{GABA}_{\mathrm{A}}$ receptors.

The concept that 5-HT inhibits defensive reactions elaborated in the dPAG is central to the hypothesis that $5-\mathrm{HT}$ has a dual role in defense (13). This theoretical construct was devised to explain seemingly inconsistent effects of 5-HT-acting drugs measured in animal models of anxiety: in punishment or inhibitory avoidance tests, response suppression is attenuated by drugs that reduce the action of 5-HT in the brain, an effect shared by typical anxiolytic agents; conversely, pro-5-HT drugs enhance the behavioral inhibition caused by the same tests. This evidence led to the suggestion that 5-HT exerts an anxiogenic action in the brain. Pointing to the opposite direction, however, the results described above with escape from aversive stimulation show that 5-HT-enhancing drugs impair escape, indicating that 5-HT decreases anxiety. To circumvent this inconsistency, we suggested (13) that these two experimental paradigms represent different defense strategies, as defined by the ethoexperimental studies carried out by Blanchard and Blanchard (19): inhibitory avoidance or conflict tests would engage forebrain neural networks that organize defense against potential threats, whereas escape tasks engage neural circuits that control primitive defense reactions against proximal threats, which are mainly integrated in the hindbrain, particularly in the dPAG. Since inhibitory avoidance is facilitated while escape is inhibited by $5-\mathrm{HT}$, this neurotransmitter is assumed to enhance defense against potential danger, but to restrain proximal defense. This organization would allow the animal to withhold conspicuous defense reactions, such as running and jumping, in situations where the predator is absent (potential threat) or at a safe distance from the prey (distant threat).

Taking it a step further, Deakin and Graeff (14) integrated defense strategy, normal emotion and related psychiatric disorder with drug responses and the underpinning brain structures. The resultant organization is summarized in Table 2.

Extending the preceding argument, Deakin and Graeff (14) suggested that 5-HT enhances anxiety by acting on the amygdala and PFC, but inhibits panic by acting on the dPAG. As described above, the pharmacological results with electrical stimulation of the dPAG and the escape task in the ETM are in agreement with the latter assumption, as is the hyperreponsiveness of $5-\mathrm{HT}_{1 \mathrm{~A}}$ and $5-\mathrm{HT}_{2 \mathrm{~A}}$ receptors localized in the dPAG caused by drug regimens that are clinically effective on PD - indicating that 5-HT is relevant for the therapeutic outcome (15). 
Table 2. Antipredator defense strategies, anatomical basis, related emotions, anxiety disorders, and their drug treatment.

\begin{tabular}{llllll}
\hline Threat & Defense strategy & Critical brain structures & Emotion & Disorder & Drug treatment \\
\hline $\begin{array}{l}\text { Uncertain } \\
\text { Conflict }\end{array}$ & $\begin{array}{l}\text { Risk assessment } \\
\text { Behavioral inhibition }\end{array}$ & $\begin{array}{l}\text { PFC } \\
\text { Septum-hippocampus }\end{array}$ & Anxiety & GAD & Anxiolytic \\
Anticipated (CS) & Freezing (no exit) & $\begin{array}{l}\text { Amygdala } \\
\text { VPAG }\end{array}$ & Anxiety & Anticipatory anxiety & $\begin{array}{l}\text { Anxiolytic } \\
\text { Antidepressant }\end{array}$ \\
& Avoidance & Amygdala & Conditioned fear & Specific phobia & None \\
Distal (US) & Escape & Medial hypothalamus & Unconditioned fear & Specific phobia & None \\
Proximal (US) & Flight or immobility & dPAG & Dread & PD & Antidepressant \\
\hline
\end{tabular}

$\mathrm{CS}=$ conditioned stimulus; US = unconditioned stimulus; PFC = prefrontal cortex; vPAG = ventral periaqueductal gray; $\mathrm{dPAG}=\mathrm{dorsal}$ periaqueductal gray; GAD = generalized anxiety disorder; PD = panic disorder. Modified from Deakin and Graeff (14).

The next question is whether serotonergic mechanisms operating in the dPAG are involved in the pathophysiology of PD. The results of a preclinical study by Johnson et al. (20) indicate that they are. In their experiments, rats were chronically infused with the GABA synthesis inhibitor l-allylglycine through a minipump placed inside the dorsomedial hypothalamus, a procedure that makes the animals responsive to lactate, like PD patients. Controls were similarly infused with the inactive enantiomer, d-allylglycine. The activation of brain structures was assessed by the c-Fos technique, and the results obtained showed that lactate increased c-Fos expression in serotonergic neurons situated in the ventrolateral part of the dorsal raphe nucleus and ventrolateral PAG of control, but not panic-prone, rats. The distribution of lactate-sensitive serotonergic neurons in control rats overlaps the set of neurons activated by stressful situations previously described by Johnson et al. (21), which project to both the dPAG and sympathomotor control areas of the rostral ventrolateral medulla. The former projection is thought to inhibit the behavioral responses and the latter, the neurovegetative changes evoked by lactate in panic-prone rats. It has also been hypothesized that such serotonergic neurons normally limit neurovegetative and behavioral responses to innocuous interoceptive and exteroceptive stimuli, and that dysfunction of this serotonergic system increases vulnerability to PAs in animals as well as humans (20).

In summary, the serotonergic hypothesis of PD pathophysiology proposes that panic patients have deficient serotonergic inhibition of neurons localized in the dPAG that organize defensive reactions to cope with proximal threats and of sympathomotor control areas of the rostral ventrolateral medulla that bring about most of the neurovegetative symptoms of the PA. Indirect human experimental evidence is compatible with this view. The first line of evidence is based on studies using the simulated public speaking (SPS) test, in which the participant is required to speak in front of a video camera while looking at her/his image on a video screen. This procedure evokes anticipatory anxiety before the speaking task begins, as well as fear during speech preparation and performance. This distinction is based on pharmacological studies showing that anticipatory anxiety is reduced by benzodiazepine anxiolytics, but fear of public speaking is resistant to anxiolytics. In turn, fear of public speaking is affected by drugs that act primarily on $5-\mathrm{HT}$, the pharmacological profile of speaking fear being similar to that of PD. For this reason, SPS is assumed to engage the same neural networks that control the PA (22).

With a modified SPS test, in which healthy volunteers had their speech recorded on an audio tape, we showed that the nonselective 5-HT receptor antagonist metergoline increased subjective anxiety, measured by a self-rating scale before and after the speaking stress, and also reduced the response to speech preparation and performance (23). Several years later, Del-Ben et al. (24) observed that panic patients likewise showed a higher degree of anticipatory anxiety and a lesser response to speaking stress than healthy controls. This similarity led to the suggestion that PD patients lacked endogenous 5-HT inhibition, thus becoming more vulnerable to PAs.

Further evidence comes from two experimental studies $(25,26)$ using a human version of the mouse defense test battery, a procedure that assesses behavioral indexes of anxiety and fear/panic separately and that has been pharmacologically validated (27). In the task designed to represent a potential threat, healthy volunteers use a forcesensing joystick to control the speed of a green dot cursor that moves within a vertical alley on a video screen, when it is trapped between two immobile red dot threat stimuli. The magnitude of approach-withdrawal oscillations during this phase was used as a measure of anxiety. In the task representing an actual threat, the average speed of the cursor while the participant was escaping from the pursuit by a single red dot threat stimulus was used as an index of fear. The results of the first study (25) showed that the benzodiazepine anxiolytic lorazepam significantly reduced approach-withdrawal oscillations during the first task, supporting the hypothesis that this task represents anxiety. In 
contrast, the same drug did not change the performance of the escape task, hypothetically related to fear. In the second study (26), the escape task was measured in participants who differed in genetic risk for PD. The genetic risk factor used was the $\mathrm{C}$ allele of the 102T/C single-nucleotide polymorphism (rs6313) within the serotonin 2A receptor gene (HTR2A) on chromosome 13q14.2. This allele is known to be associated with increased susceptibility to pure but not comorbid PD, as well as to an increased magnitude of panic symptoms. The main finding was that carriers of the $C$ risk allele showed significantly greater escape intensity than individuals devoid of this allele. This molecular genetic investigation, together with the preceding pharmacological results, support the hypothesis that PD stems from alterations in the brain systems governing escape behavior, which are modulated by $5-\mathrm{HT}$.

Although the evidence presented above does not permit anatomical localization, reported neuroimaging results have suggested anomalies of $5-\mathrm{HT}$ neurotransmission in the midbrain of panic patients. The study most pertinent to the present discussion was conducted by Maron et al. (28) and measured the serotonin membrane transporter (5-HTT) binding in the brain of patients with PD by means of single-photon emission computed tomography (SPECT) with a radioligand that specifically labels the 5-HTT. Patients with symptomatic PD had a significantly decreased 5-HTT binding in the midbrain, temporal lobes and thalamus compared to normal controls. Patients with PD in remission had normal 5-HTT binding in the midbrain and temporal lobes, but still showed a significant decrease in thalamic 5-HTT. The authors suggested that such reduced density of brain 5-HTT may reflect a deficit of neuronal 5-HT, or a compensatory process in the 5-HT system attempting to increase the availability of synaptic 5-HT. The deficits in the midbrain and in the temporal lobes may be related to clinical symptoms, since they were absent in the patients in remission, whereas the reduced 5-HTT in the thalamus may rather be a marker of interoceptive sensitivity and anticipatory anxiety.

There is also a reported PET study (29) with a selective $5-\mathrm{HT}_{1 \mathrm{~A}}$ receptor $\left(5-\mathrm{HT}_{1 \mathrm{~A}} \mathrm{R}\right)$ radioligand that assessed central $5-\mathrm{HT}_{1 \mathrm{~A}} \mathrm{R}$ binding in symptomatic $\mathrm{PD}$ patients compared to matched healthy controls. Panic patients showed lower $5-\mathrm{HT}_{1 \mathrm{~A}} \mathrm{R}$ density in the median raphe and in the anterior and posterior cingulate gyrus than controls. These results provide in vivo evidence for the involvement of $5-\mathrm{HT}_{1 \mathrm{~A}} \mathrm{Rs}$ in the pathophysiology of PD. Since the dPAG receives serotonergic fibers from the dorsal raphe nucleus, the abnormality of $5-\mathrm{HT}_{1 \mathrm{~A}} \mathrm{R}$ in the raphe area may result in functional changes in the dPAG neurons that control proximal defense, hypothetically involved in PAs.

\section{Opioids and Panic}

The connection between opioids and PD has been made within the amplified false suffocation alarm (FSA) theory proposed by Preter and Klein (30). In the original version of the FSA theory (31), Klein proposed that the spontaneous PA is due to the misinterpretation by a hypersensitive $\mathrm{CO}_{2}$ detector that triggers a suffocation alarm, producing sudden respiratory distress. Among other arguments, Klein highlighted the facts that dyspnea, air hunger and urge to flee are cardinal symptoms of PAs, and that PD patients present baseline respiratory abnormalities and a higher rate of comorbid and antecedent respiratory diseases.

Critical tests of the FSA theory have been made with chemical panicogenic agents that induce PAs in PD patients at rates far higher than in healthy individuals. Among these challenges, lactate and $\mathrm{CO}_{2}$ inhalation at high concentrations are the most selective panicogens (32). Both treatments are assumed to elevate intracellular $\mathrm{pCO}_{2}$, triggering the suffocation alarm (31). A significant finding from this line of research was the verification that the PA induced by either lactate or $\mathrm{CO}_{2}$, stressful as it is, does not activate the hypothalamic-pituitary-adrenal (HPA) axis, similarly to the natural PA (33). This establishes a connection between the FSA and the Deakin-Graeff theories, since it has been shown that the speaking fear in the SPS test, which is assumed to engage the same neural networks involved in the PA (see above), also does not increase salivary or plasma levels of cortisol, in contrast to anticipatory anxiety $(34,35)$.

Similar results have been obtained in animal models of panic. Electrical stimulation of the rat dPAG eliciting freezing or flight behavior did not increase the plasma concentration of the stress hormones adrenocorticotropin (ACTH) and prolactin; even a 5-min stimulation of the dPAG at the flight threshold intensity did not change ACTH levels significantly (36). Nevertheless, contrary results have also been reported (37). In the ETM, performance of the escape task, related to panic, did not release corticosterone into the blood stream; in contrast, the avoidance task, related to anxiety, increased the plasma level of the same stress hormone (38). Since the HPA axis is not activated by manipulations that are thought to activate the suffocation alarm system as well as those that are believed to stimulate the dPAG, it is possible that suffocation may engage the dPAG in the same way as other kinds of proximal threat, a notion already acknowledged by Deakin and Graeff (14).

Supporting the last view, preclinical results obtained by Schimitel et al. (39) showed that anoxia produced by sublethal doses of iv potassium cyanide (KCN) produced freezing and flight behavior and potentiated panic-like responses in rats elicited by PAG electrical stimulation. Moreover, KCN-evoked defensive responses were either abolished or markedly attenuated following electrolytic lesion of the caudal PAG. In contrast, exposure to $13 \%$ $\mathrm{CO}_{2}$ produced only a significant reduction of grooming and attenuated PAG-evoked panic-like responses. However, exposure to either 8 or $13 \% \mathrm{CO}_{2}$ produced a marked dosedependent facilitation of $\mathrm{KCN}$-induced flight behavior. It was 
suggested that the caudal PAG harbors an anoxia-sensitive suffocation alarm system, the dysfunction of which renders the rat hyperresponsive to $\mathrm{CO}_{2}$.

The amplified FSA theory emphasizes a role for endogenous opioids in both respiratory misregulation and separation distress - another factor that is associated with vulnerability to PA (40). As to respiration, several reported results have shown that endogenous opioids are activated in hypoxic or hypercapnic respiratory distress, decrease respiratory sensitivity to $\mathrm{CO}_{2}$, and increase survival under hypoxic and hypercapnic conditions (for references, see Preter and Klein, 30). The case for opioids and separation distress is more complex. Klein and Fink (1) found that $50 \%$ of hospitalized patients with a diagnosis of agoraphobia reported severe early separation anxiety that frequently prevented school attendance, and in this group panic was often precipitated by separation or bereavement. As a consequence, they hypothesized a developmental pathophysiological link between separation anxiety and PD with subsequent agoraphobia. Supporting this suggestion, a controlled, long-term, direct, blind, clinical interview follow-up carried out by Klein (40) in separation-anxious, school-phobic children showed that the only significant finding was an increased PD rate later in life.

Again, the increased susceptibility to PA determined by early separation may also be mediated by PAG mechanisms, since a preclinical study (41) showed that rats separated from their mothers at an early age - $3 \mathrm{~h}$ per day during the 21 days of lactation - became more sensitive to elicitation of panic-like behavior by electrical stimulation of the dPAG on the 65th day postpartum. Compared to controls, separated rats showed a marked reduction in the thresholds for immobility, exophthalmus, trotting, galloping, and jumping elicited by electrical dPAG stimulation.

The connection between separation distress and opioids is based on the research by Panksepp et al. (42), who have systematically studied the neurobiology of social bonding and separation in laboratory animals. Among their findings stands the verification that low doses of the exogenous opiates oxymorphone and morphine reduce crying and motor agitation during brief periods of social isolation in puppies. Since such effects could be obtained in the absence of any gross behavioral change, it was suggested that brain opiates may regulate the emotions arising from social separation (43). Similar results have been reported in primates (44), with a low dose of morphine significantly decreasing separation distress vocalizations in rhesus monkeys without changing motor activity. Furthermore, this effect was blocked by a low dose of the opioid receptor antagonist naloxone and a higher dose of naloxone increased distress calls by itself, suggesting a regulatory role of endogenous opioids. Connecting separation-distress calls with panic are J.P. Scott's findings, in beagles, showing that among several psychoactive drugs tested only the antipanic agent imipramine selectively reduced distress vocalizations at non-sedating doses (quoted by Preter and Klein, 30).

Assuming the central regulatory role of opioids in disordered breathing and separation distress, the amplified FSA theory proposes that there is a functional deficit of endogenous opioids in PD (30). For empirical validation of this theory, human experimental studies were carried out to verify whether pretreatment with the opioid antagonist naloxone would render healthy volunteers as susceptible to lactate-induced PA as PD patients. The results of an open pilot study showed that in 8 of 12 normal subjects, infusion of a high dose of naloxone $(2 \mathrm{mg} / \mathrm{kg}$ ) followed by lactate caused respiratory changes similar to those observed during clinical PAs. Four of the subjects that received the same lactate injection after placebo did not show tidal volume increment (45). Even more convincing, a further study used randomized cross-over sequences of the same dose ( $2 \mathrm{mg} / \mathrm{kg}$ ) of intravenous naloxone followed by lactate, or saline followed by lactate, given to 25 healthy volunteers. Respiration was objectively measured, and subjective symptomatology was also recorded. Whether separation and personal loss during childhood affected naloxone-induced respiratory changes was also explored. As expected, the results showed that naloxone pretreatment enhanced tidal volume and the symptomatic response to lactate. In addition, naloxone potentiation of lactate was less marked in volunteers who had experienced childhood parental loss, possibly because the endogenous opioid function was already reduced in these subjects (46). Altogether, these results support the hypothesis that endogenous opioids buffer normal subjects from the behavioral and physiological effects of lactate and, conversely, their deficit may bring about the suffocation sensitivity and separation anxiety shown by panic patients (30).

\section{5-HT and Opioids}

Summing up the evidence discussed above, it may be concluded that the susceptibility to PA of PD patients is due to a functional deficit of either a serotonergic or an opioidergic system that restrains PAs in healthy individuals. Assuming the pivotal role of the dPAG in the regulation of PAs, the question arises of whether 5-HT and opioids are able to interact within this brain area. To investigate the latter possibility, a series of experiments were carried out by Roncon et al. (47), in which rats were tested in the ETM model of anxiety and panic. The method used has been described fully before (see, e.g., Zanoveli et al., 48). Briefly, the ETM has three arms of equal dimensions; one arm, enclosed by walls, perpendicular to two opposed open arms. For two consecutive days, the animals are gently handled for $5 \mathrm{~min}$, and on the last day, $24 \mathrm{~h}$ before the test, each animal is pre-exposed to one of the open arms of the ETM for $30 \mathrm{~min}$. On the test day, following drug treatment, the rat is placed at the end of the enclosed arm facing the intersection of the arms. The time taken to leave this arm 
with the four paws is recorded (Baseline). The same measurement is repeated twice at 30 -s intervals (Avoidance 1 and Avoidance 2). Following avoidance training (30 s), the rat is placed at the end of the open arm to which it had been previously exposed, and the latency to leave this arm with the four paws is recorded three consecutive times (Escape $1-3$ ) at 30-s inter-trial intervals. A cut-off time of $300 \mathrm{~s}$ is set for the avoidance and escape latencies.

The first experiment carried out by Roncon et al. (47) tested whether pretreatment with an intraperitoneal injection of naloxone $(1 \mathrm{mg} / \mathrm{kg})$ changes the effect of chronic treatment $(10 \mathrm{mg} / \mathrm{kg}$, ip, daily for 21 days) with fluoxetine on ETM performance. The results showed that fluoxetine significantly increased escape latency, which is interpreted as a panicolytic-like effect. In addition, naloxone did not affect escape, but when given before fluoxetine it antagonized its panicolytic effect. This result suggests that the antipanic effect of the serotonergic antidepressant is dependent on endogenous opioids.

Since the antipanic action of fluoxetine is likely to be exerted in the dPAG (15), the second experiment tested whether the effect of systemic fluoxetine on escape latency could be antagonized by naloxone microinjected into the dPAG. The results showed that $0.2 \mu \mathrm{g}$ (in $0.5 \mu \mathrm{L}$ ) of intradPAG naloxone did not affect the escape latency, but was able to antagonize the antipanic effect of fluoxetine when given as pretreatment. This result suggests that the antipanic effect of fluoxetine involves endogenous opioids that operate within the dPAG.

Because the antipanic effect of fluoxetine is likely to be due to increased serotonergic function in the dPAG (48), the third experiment assessed the influence of naloxone on the antipanic effect of 5-HT when both were injected into the dPAG. The results showed that the escape impairment produced by $5-\mathrm{HT}(20 \mathrm{nmol} / 0.5 \mu \mathrm{L})$ was attenuated by previous administration of naloxone $(0.2 \mu \mathrm{g} / 0.5 \mu \mathrm{L})$. This result indicates that the antipanic effect of $5-\mathrm{HT}$ in the dPAG needs activation of local endogenous opioids to be expressed.

It is worth remarking that the effects of this drug on the ETM were specific for escape, since no significant changes occurred in either the avoidance task or locomotion, the latter being measured inside a square arena soon after the ETM test.

The main results of the study by Roncon et al. (47) are shown in Figure 1.

Further research is needed to establish the cellular and molecular basis of the interaction between $5-\mathrm{HT}$ and endogenous opioids that is likely to take place in the dPAG. Nevertheless, there are some clues that deserve consideration. For instance, Preter and Klein (30) remarked that only high doses of naloxone were able to potentiate the panic-inducing effect of lactate in healthy volunteers, and since naloxone blocks the $\mu$ opioid receptor at lower concentrations than those needed to block the $\delta$ receptor,

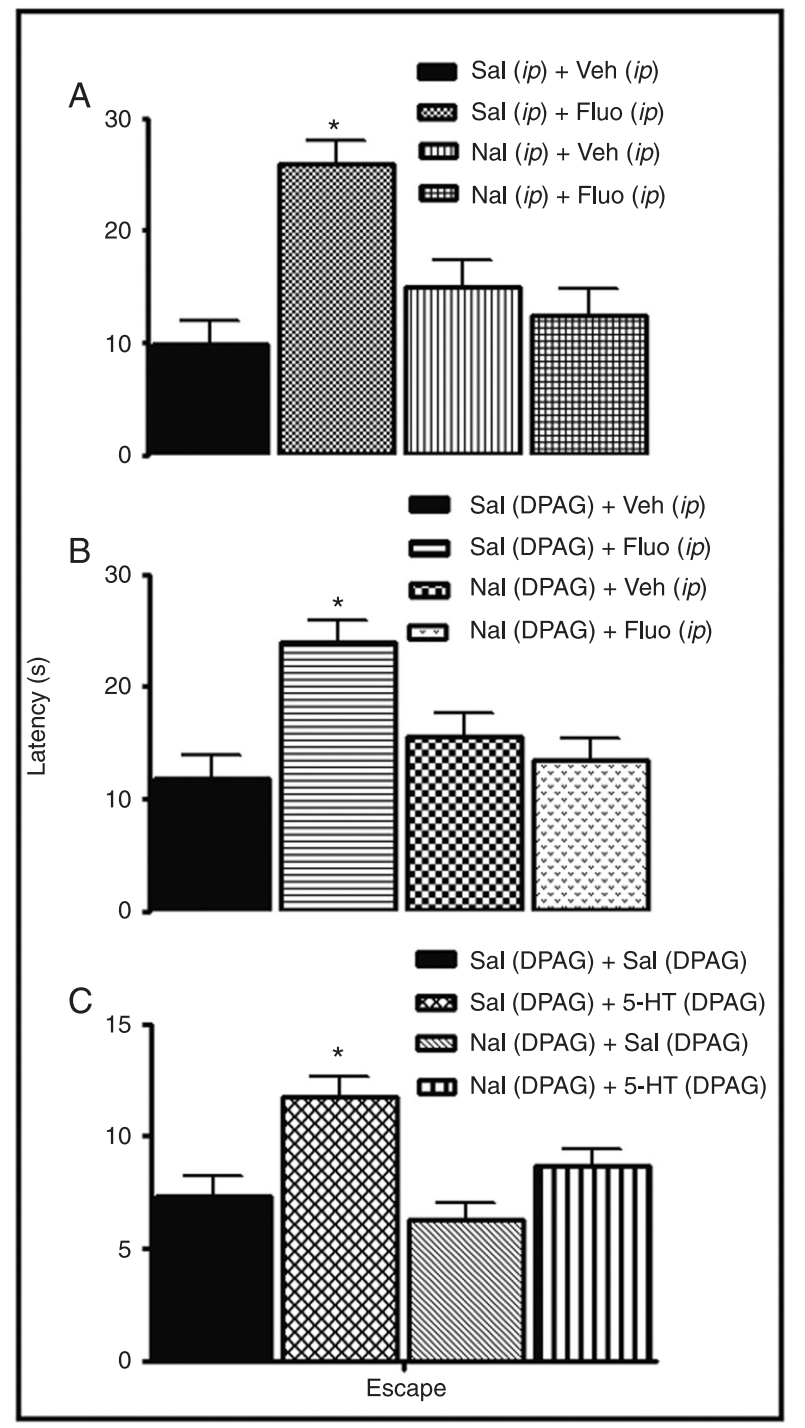

Figure 1. Naloxone (Nal) antagonism of the antipanic effect of serotonergic drugs in the one-way escape task performed on the elevated T-maze. Panel A, Nal administered intraperitoneally (ip) $=1 \mathrm{mg} / \mathrm{kg}$ naloxone, ip; Fluo $=10 \mathrm{mg} / \mathrm{kg}$, ip, of fluoxetine daily for 21 days; Sal = saline; Veh = vehicle. Panel $B$, Nal $($ DPAG $)=0.2$ $\mu \mathrm{g}$ naloxone into the dorsal periaqueductal gray. Panel $C, 5-\mathrm{HT}$ (DPAG): $8 \mu \mathrm{g}$ serotonin intra-DPAG. ${ }^{*} \mathrm{P}<0.05$ compared to all other groups (Fisher post hoc test). $\mathrm{N}=6-8$ rats. Data are reported as means \pm SEM of combined measures of the three escape trials calculated from data reported by Roncon et al. (47).

they suggested that the latter receptor type was mainly involved in the panic-buffering action of endogenous opioids. Interestingly, Leu-enkephalin has a higher affinity for $\delta$ than for $\mu$ opioid receptors, and an interaction between this endogenous opioid and 5-HT has already been reported (49). In this study, the antinociceptive effect induced by $5-\mathrm{HT}$ microinjected into the nucleus accumbens was 
blocked by naloxone injected into the same site. In addition, it was verified that the antinociception elicited by intra-accumbens injection of [d-Ala $\left.{ }^{2}, \mathrm{~d}-\mathrm{Leu}^{5}\right]$-enkephalin was not affected by cinanserin, a 5-HT blocking agent. It was suggested that 5-HT activates an enkephalinergic mechanism within the nucleus accumbens, resulting in the antinociceptive effect. Therefore, Leu-enkephalin may be a worthy candidate for participating in the serotonin-opioid interplay that we are suggesting to occur in the dPAG. Nevertheless, $\beta$-endorphin is another possibility to be kept in mind, since a neurohistochemical study detected the presence of varicose fibers positive for $\beta$-endorphin and/or Leu-enkephalin in the rat dPAG (50). Because varicosities are characteristic of monoaminergic nerve fibers (51), the possibility of 5-HT and opioids being cotransmitters (52) should also be considered.

\section{Conclusion}

The evidence reviewed here suggests that the vulnerability to PAs that characterizes PD may be the result of faulty buffering mechanisms. Two of them have been hypothesized on the basis of empirical evidence gathered in experimental animals and in human beings. The first is a serotonergic input that restrains neurons in the dPAG that organize behavioral reactions to cope with a proximal threat, and that inhibits sympathomotor control areas of the rostral

\section{References}

1. Klein DF, Fink M. Psychiatric reaction patterns to imipramine. Am J Psychiatry 1962; 119: 432-438.

2. American Psychiatric Association. Diagnostic and statistical manual of mental disorders. 4th edn. Washington: American Psychiatric Press; 2000.

3. Del-Ben CM, Graeff FG. Panic disorder: is the PAG involved? Neural Plast 2009; 2009: 108135.

4. Protopopescu X, Pan H, Tuescher O, Cloitre M, Goldstein $M$, Engelien A, et al. Increased brainstem volume in panic disorder: a voxel-based morphometric study. Neuroreport 2006; 17: 361-363.

5. Uchida RR, Del-Ben CM, Busatto GF, Duran FL, Guimaraes FS, Crippa JA, et al. Regional gray matter abnormalities in panic disorder: a voxel-based morphometry study. Psychiatry Res 2008; 163: 21-29.

6. Fujiwara A, Yoshida T, Otsuka T, Hayano F, Asami T, Narita $\mathrm{H}$, et al. Midbrain volume increase in patients with panic disorder. Psychiatry Clin Neurosci 2011; 65: 365-373.

7. Reiman EM, Raichle ME, Robins E, Mintun MA, Fusselman MJ, Fox PT, et al. Neuroanatomical correlates of a lactateinduced anxiety attack. Arch Gen Psychiatry 1989; 46: 493500.

8. Javanmard M, Shlik J, Kennedy SH, Vaccarino FJ, Houle S, Bradwejn J. Neuroanatomic correlates of CCK-4-induced panic attacks in healthy humans: a comparison of two time points. Biol Psychiatry 1999; 45: 872-882.

9. Sakai $Y$, Kumano H, Nishikawa M, Sakano $Y$, Kaiya H, ventrolateral medulla that give rise to the neurovegetative symptoms of the PA (20). The second is an endogenous opioidergic system that modulates the suffocation alarm monitor and reduces social separation distress (30). The results cited above, suggesting that the antipanic action of 5-HT in the dPAG involves local endogenous opioids, indicate that this brain area may be the fulcrum of both the serotonergic and the opioidergic regulation of panic, highlighting once again the pivotal role of the $\mathrm{APAG}$ in the pathophysiology of PD $(3,13,14)$.

The present perspective on the pathophysiology of PD may have clinical implications, since it points to the use of opioid agonists in the management of PD. Although longterm treatment with conventional opioids is questionable due to abuse liability, mixed agonists-antagonists or selective opioid-receptor agonists may be worth investigating for either alternative or coadjuvant treatment of PD.

\section{Acknowledgments}

Research supported by FAPESP (Projeto Temático \#2007/03685-3, coordinated by Francisco Silveira Guimarães). F.G. Graeff is the recipient of research fellowships from CNPq and FAEPA. I am deeply indebted to Neil McNaughton and Bill Deakin for helpful comments and suggestions.
Imabayashi E, et al. Changes in cerebral glucose utilization in patients with panic disorder treated with cognitivebehavioral therapy. Neuroimage 2006; 33: 218-226.

10. Mobbs D, Petrovic P, Marchant JL, Hassabis D, Weiskopf N, Seymour B, et al. When fear is near: threat imminence elicits prefrontal-periaqueductal gray shifts in humans. Science 2007; 317: 1079-1083.

11. Mobbs D, Marchant JL, Hassabis D, Seymour B, Tan G, Gray $\mathrm{M}$, et al. From threat to fear: the neural organization of defensive fear systems in humans. J Neurosci 2009; 29: 12236-12243.

12. McNaughton N, Corr PJ. A two-dimensional neuropsychology of defense: fear/anxiety and defensive distance. Neurosci Biobehav Rev 2004; 28: 285-305.

13. Graeff FG. Neurotransmitters in the dorsal periaqueductal gray and animal models of panic anxiety. In: Briley M, File SE (Editors), New concepts in anxiety. London: MacMillan Press; 1991. p 288-312.

14. Deakin JF, Graeff FG. 5-HT and mechanisms of defence. $J$ Psychopharmacol 1991; 5: 305-315.

15. Graeff FG, Zangrossi $H$ Jr. The dual role of serotonin in defense and the mode of action of antidepressants on generalized anxiety and panic disorders. Cent Nerv Syst Agents Med Chem 2010; 10: 207-217.

16. Graeff FG. On serotonin and experimental anxiety. Psychopharmacology 2002; 163: 467-476.

17. Graeff FG, Del-Ben CM. Neurobiology of panic disorder: 
from animal models to brain neuroimaging. Neurosci Biobehav Rev 2008; 32: 1326-1335.

18. Graeff FG. Serotonin, the periaqueductal gray and panic. Neurosci Biobehav Rev 2004; 28: 239-259.

19. Blanchard DC, Blanchard RJ. Ethoexperimental approaches to the biology of emotion. Annu Rev Psychol 1988; 39: 4368.

20. Johnson P, Lowry C, Truitt W, Shekhar A. Disruption of GABAergic tone in the dorsomedial hypothalamus attenuates responses in a subset of serotonergic neurons in the dorsal raphe nucleus following lactate-induced panic. $J$ Psychopharmacol 2008; 22: 642-652.

21. Johnson PL, Lightman SL, Lowry CA. A functional subset of serotonergic neurons in the rat ventrolateral periaqueductal gray implicated in the inhibition of sympathoexcitation and panic. Ann N Y Acad Sci 2004; 1018: 58-64.

22. Graeff FG, Parente A, Del-Ben CM, Guimaraes FS. Pharmacology of human experimental anxiety. Braz J Med Biol Res 2003; 36: 421-432.

23. Graeff FG, Zuardi AW, Giglio JS, Lima Filho EC, Karniol IG. Effect of metergoline on human anxiety. Psychopharmacology 1985; 86: 334-338.

24. Del-Ben CM, Vilela JA, Hetem LA, Guimaraes FS, Graeff FG, Zuardi AW. Do panic patients process unconditioned fear vs. conditioned anxiety differently than normal subjects? Psychiatry Res 2001; 104: 227-237.

25. Perkins AM, Ettinger U, Davis R, Foster R, Williams SC, Corr PJ. Effects of lorazepam and citalopram on human defensive reactions: ethopharmacological differentiation of fear and anxiety. J Neurosci 2009; 29: 12617-12624.

26. Perkins AM, Ettinger U, Williams SC, Reuter M, Hennig J, Corr PJ. Flight behaviour in humans is intensified by a candidate genetic risk factor for panic disorder: evidence from a translational model of fear and anxiety. Mol Psychiatry 2011; 16: 242-244

27. Griebel G, Blanchard DC, Agnes RS, Blanchard RJ. Differential modulation of antipredator defensive behavior in Swiss-Webster mice following acute or chronic administration of imipramine and fluoxetine. Psychopharmacology 1995; 120: 57-66

28. Maron E, Kuikka JT, Shlik J, Vasar V, Vanninen E, Tiihonen J. Reduced brain serotonin transporter binding in patients with panic disorder. Psychiatry Res 2004; 132: 173-181.

29. Neumeister A, Bain E, Nugent AC, Carson RE, Bonne O, Luckenbaugh DA, et al. Reduced serotonin type $1 \mathrm{~A}$ receptor binding in panic disorder. $J$ Neurosci 2004; 24: 589-591.

30. Preter M, Klein DF. Panic, suffocation false alarms, separation anxiety and endogenous opioids. Prog Neuropsychopharmacol Biol Psychiatry 2008; 32: 603-612.

31. Klein DF. False suffocation alarms, spontaneous panics, and related conditions. An integrative hypothesis. Arch Gen Psychiatry 1993; 50: 306-317.

32. Bourin M, Baker GB, Bradwejn J. Neurobiology of panic disorder. J Psychosom Res 1998; 44: 163-180.

33. Graeff FG, Garcia-Leal C, Del-Ben CM, Guimaraes FS. Does the panic attack activate the hypothalamic-pituitaryadrenal axis? An Acad Bras Cienc 2005; 77: 477-491.

34. Garcia-Leal C, Parente AC, Del-Ben CM, Guimaraes FS, Moreira AC, Elias LL, et al. Anxiety and salivary cortisol in symptomatic and nonsymptomatic panic patients and healthy volunteers performing simulated public speaking. Psychiatry Res 2005; 133: 239-252.
35. Garcia-Leal C, Del-Ben CM, Leal FM, Graeff FG, Guimaraes FS. Escitalopram prolonged fear induced by simulated public speaking and released hypothalamic-pituitary-adrenal axis activation. J Psychopharmacol 2010; 24: 683-694.

36. Schenberg LC, Dos Reis AM, Ferreira Povoa RM, Tufik S, Silva SR. A panic attack-like unusual stress reaction. Horm Behav 2008; 54: 584-591.

37. Lim LW, Blokland A, van Duinen M, Visser-Vandewalle V, Tan S, Vlamings R, et al. Increased plasma corticosterone levels after periaqueductal gray stimulation-induced escape reaction or panic attacks in rats. Behav Brain Res 2011; 218: 301-307.

38. Graeff FG, Zangrossi H Jr. The hypothalamic-pituitaryadrenal axis in anxiety and panic. Psychol Neurosci 2010; 3: 3-8.

39. Schimitel FG, de Almeida GM, Pitol DN, Armini RS, Tufik $S$, Schenberg LC. Evidence of a suffocation alarm system within the periaqueductal gray matter of the rat. Neuroscience 2012; 200: 59-73.

40. Klein RG. Is panic disorder associated with childhood separation anxiety disorder. Clin Neuropsychopharmacol 1995; 18 (Suppl 2): 7-14.

41. Santos JWQ, Müller CT, Bernabé CS, Rosa CA, Mendonça VA, Schenberg LC. Mother deprivation facilitates and learned helplessness inhibits the defensive behaviors produced by electrical stimulation of the dorsal periaqueductal gray matter (DPAG) of adult rats. XXVI Annual Meeting of Brazilian Federation of Societies of Experimental Biology. Rio de Janeiro: FESBE; 2011. Abstract 23.214.

42. Panksepp J, Nelson E, Bekkedal M. Brain systems for the mediation of social separation-distress and social-reward. Evolutionary antecedents and neuropeptide intermediaries. Ann N Y Acad Sci 1997; 807: 78-100.

43. Panksepp J, Herman B, Conner R, Bishop P, Scott JP. The biology of social attachments: opiates alleviate separation distress. Biol Psychiatry 1978; 13: 607-618.

44. Kalin NH, Shelton SE, Barksdale CM. Opiate modulation of separation-induced distress in non-human primates. Brain Res 1988; 440: 285-292.

45. Sinha SS, Goetz RR, Klein DF. Physiological and behavioral effects of naloxone and lactate in normal volunteers with relevance to the pathophysiology of panic disorder. Psychiatry Res 2007; 149: 309-314.

46. Preter M, Lee SH, Petkova E, Vannucci M, Kim S, Klein DF. Controlled cross-over study in normal subjects of naloxonepreceding-lactate infusions; respiratory and subjective responses: relationship to endogenous opioid system, suffocation false alarm theory and childhood parental loss. Psychol Med 2011; 41: 385-393.

47. Roncon CM, Biesdorf C, Santana RG, Zangrossi H Jr, Graeff FG, Audi EA. The panicolytic-like effect of fluoxetine in the elevated T maze is mediated by serotonin-induced activation of endogenous opioids in the periaqueductal gray. $J$ Psychopharmacol 2012; Jan 24 [Epub ahead of print].

48. Zanoveli JM, Pobbe RL, de Bortoli V, Carvalho MC, Brandão $\mathrm{ML}$, Zangrossi H Jr. Facilitation of 5-HT1A-mediated neurotransmission in dorsal periaqueductal grey matter accounts for the panicolytic-like effect of chronic fluoxetine. Int J Neuropsychopharmacol 2010; 13: 1079-1088.

49. Xuan YT, Shi YS, Zhou ZF, Han JS. Studies on the mesolimbic loop of antinociception-II. A serotonin-enkephalin interaction in the nucleus accumbens. Neuroscience 1986; 
19: 403-409

50. Osaki MY, Castellan-Baldan L, Calvo F, Carvalho AD, Felippotti TT, de Oliveira R, et al. Neuroanatomical and neuropharmacological study of opioid pathways in the mesencephalic tectum: effect of mu(1)- and kappa-opioid receptor blockade on escape behavior induced by electrical stimulation of the inferior colliculus. Brain Res 2003; 992:
179-192.

51. Hokfelt T. Looking at neurotransmitters in the microscope. Prog Neurobiol 2010; 90: 101-118.

52. Dyakonova V, Carlberg M, Sakharov D, Elofsson R. Anatomical basis for interactions of enkephalins with other transmitters in the CNS of a snail. J Comp Neurol 1995; 361: 38-47. 